\title{
Use of Exercise Classics in Physical Education Classes for the Development of Vestibular Stability of Schoolchildren
}

\author{
Polevoy G. G. ${ }^{1,2}$ \\ ${ }^{1}$ Moscow Aviation Institute, National Research University, Moscow, Russia \\ ${ }^{2}$ Vyatka State University, Kirov, Russia
}

Received December 13, 2020; Revised January 8, 2021; Accepted February 24, 2021

\section{Cite This Paper in the following Citation Styles}

(a): [1] Polevoy G. G. , "Use of Exercise Classics in Physical Education Classes for the Development of Vestibular Stability of Schoolchildren," International Journal of Human Movement and Sports Sciences, Vol. 9, No. 2, pp. 180-184, 2021. DOI: 10.13189/saj.2021.090203.

(b): Polevoy G. G. (2021). Use of Exercise Classics in Physical Education Classes for the Development of Vestibular Stability of Schoolchildren. International Journal of Human Movement and Sports Sciences, 9(2), 180-184. DOI: 10.13189/saj.2021.090203.

Copyright $(2021$ by authors, all rights reserved. Authors agree that this article remains permanently open access under the terms of the Creative Commons Attribution License 4.0 International License

\begin{abstract}
Aim: to determine the influence of exercise Classics on the development of vestibular stability of schoolchildren aged 9-10. Methods: the study was conducted over a period of 9 months, and 40 9-10-year-old schoolchildren took part in. Physical education classes were held 2 times a week for 40 minutes each lesson. The level of development of coordination abilities was assessed on the "Shuttle run" test, and the indicators of vestibular stability on the "Turns on the gym bench" test. The programs bio-stat 2009, Microsoft excel 2016 and t-student were used for mathematical and statistical processing of results. Results: at the beginning of the pedagogical experiment, the indicators of school children between the groups did not have significant differences $(\mathrm{P}>0.05)$. At the end of the study, the indicators in both groups improved. In $\mathrm{CG}$, in the Shuttle run test, the indicators improved from $10.2 \pm 0.6$ to $9.9 \pm 0.5(\mathrm{P}>0.05)$; and in the vestibular stability test, the indicators improved by $2.9 \%(\mathrm{P}>0.05)$. In EG, in the "Shuttle run $3 \times 10 \mathrm{~m}$ " test, performance improved from $9.9 \pm 0.5$ to $8.5 \pm 0.4(\mathrm{P}<0.05)$, and in the "Turns on the gym bench" test, performance improved by $34.8 \%$. These results indicate the effectiveness of using exercise Classics in physical education lessons in working with younger schoolchildren. Conclusion: if you perform a Classical exercise in physical education classes at school, you will improve not only the indicators of coordination abilities, but also the vestibular stability of schoolchildren.
\end{abstract}

Keywords Vestibular Stability, Coordination Abilities, Schoolchildren, Physical Culture, Classics

\section{Introduction}

Problems of health, physical education and sports are relevant, especially at school age [1-2]. Modern literature increasingly emphasizes the importance of physical culture in school for the health of children of different ages [3-4]. From the first lessons in physical culture, the main goal of the teacher is a comprehensive harmonious development of schoolchildren. A physical education lesson at school is the main and centralized form of physical exercise. Schoolchildren get the necessary motor activity, especially at early school age, it is in the classroom. Full development of school-age children without active physical training is impossible. Each lesson solves educational and health-improving tasks, forms schoolchildren interest in physical exercises, and encourages them to be active [5-6].

Modern physical education programs in schools, unfortunately, do not take into account certain features, such as the lack of gyms or equipment in schools [7].

You can increase the motor density of a physical education lesson at school, as well as increase the 
emotional background of the lesson with the help of exercise Classics. The exercise Classics is unique because of its simplicity and the fact that it does not require additional equipment [8].

In addition, the exercise Classics allow you to effectively use an individual approach that is necessary in working with children, since each person is unique and has its own level of development [9-10]. Thus, we suggest only minor additions to the standard physical education program for schoolchildren in grades $1-11$, in contrast to some studies that suggest new methodics [11-12].

A favorable period for the development of most physical abilities (strength, speed, endurance, flexibility and dexterity) is Junior school age [13]. This is especially true for coordination abilities. Coordination abilities are the ability to efficiently coordinate movements when building new motor actions and rearrange movement when switching to another action in accordance with the requirements of changing conditions. For human life, these abilities are necessary from early childhood. They allow you to optimally solve motor problems both in everyday life and in sports. Coordination abilities are a prerequisite for mastering complex elements of sports equipment [14-16].

The positive influence of motor activity on the development of mental processes during physical education and sports has been proven by some studies. The authors emphasize the importance of physical education and sports for human thinking and cognitive abilities [17-19]. In addition, there are studies that confirm the effectiveness of physical education and sports in relation to positive ratings during training sessions [20-21].

However, it is necessary to study the influence of exercise Classics on the vestibular stability of primary school children.

Aim - to determine the influence of exercise Classics on the development of vestibular stability of schoolchildren aged 9-10.

The hypothesis of the study is that if the exercise Classics is used in physical education lessons, the indicators of vestibular stability of younger schoolchildren will improve.

\section{Materials and Methods}

Participants:

All the children had good health, were allowed to take physical education classes and were engaged in regular school (No. 60) in the city of Kirov (Russia). At the time of the pedagogical experiment, boys and girls (40 people) were studying in the third grade, and the age of children is 9-10 years old.

All procedures met the ethical standards of the 1964 Declaration of Helsinki. Informed consent was obtained from all parents of the children included in the study.
Procedure:

The pedagogical research lasted during the school year (September-may). Physical education classes were held twice a week. Each lesson lasted 40 minutes. A total of 56 lessons were conducted.

Before the beginning of the pedagogical experiment 2 groups were formed:

The first group included schoolchildren of class $3 \mathrm{~A}$. This group was a control group (CG). The number of schoolchildren in this group is 20 . Boys and girls were engaged in physical education according to the usual physical education program for secondary schools [7]. The second group included schoolchildren of class $3 \mathrm{~B}$. This group was experimental (EG). The number of schoolchildren in this group was also 20. Children in this class were engaged in the usual mode, according to the usual program; but in addition to each lesson in physical education, they performed the exercise Classics (table 1).

Table 1. Exercise "Classic's"

\begin{tabular}{|l|l|l|l|l|l|l|l|l|l|l|}
\hline 8 & 2 & 7 \\
\hline 1 & 4 & 3 \\
\hline 9
\end{tabular}

Exercise "Classic's":

In the gym, there are three large squares on the floor. The side of one square is $180 \mathrm{~cm}$. Inside each large square there are nine small squares, the side of the small square is $60 \mathrm{~cm}$. Inside each small square are numbers from 1 to 9.

Task: the schoolchild must use jumps from square to square to get from number 1 to number 2 , then to number 3 , and so on, to number 9. After that, it should jump on the same squares in reverse order (from number 9 to number 1). You can move around the squares in any way (from one leg to the other, jump on one leg or on two). If the schoolchild makes a mistake, he returns to the previous square. During the lesson, each schoolchild must overcome three large squares. The numbers in the squares must be changed by the teacher before each lesson. You can perform the exercise in any part of the lesson.

Before and after the pedagogical experiment all schoolchildren took control tests:

1. Shuttle run $3 \times 10 \mathrm{~m}$ (indicator of coordination abilities) [22].

2. Turns on the gym bench (indicators of vestibular stability) [23].

The schoolchildren must perform the exercise on a narrow surface of the gym bench. The number of turns is calculated, with an accuracy of 0.5 turns on the bench. If the schoolchildren fall, then he needs to get up and continue performing the exercise. Result: the number of turns in 20 seconds, the better of two attempts is counted. 
Table 2. Indicators of coordination abilities and vestibular stability of children 9-10 years' old

\begin{tabular}{|c|c|c|c|c|c|c|c|c|}
\hline \multirow{2}{*}{ Test } & \multicolumn{4}{|c|}{ CG } & \multicolumn{4}{|c|}{ EG } \\
\hline & Before & After & $\%$ & $\mathbf{P}$ & Before & After & $\%$ & $\mathbf{P}$ \\
\hline Shuttle run $3 \times 10 \mathrm{~m}(\mathrm{~s})$ & $10.2 \pm 0.6$ & $9.9 \pm 0.5$ & 2.9 & $\mathrm{P}>0.05$ & $9.9 \pm 0.5$ & $8.5 \pm 0.4$ & 14.1 & $\mathrm{P}<0.05$ \\
\hline $\begin{array}{l}\text { Turns on the gym } \\
\text { bench (number of } \\
\text { times) }\end{array}$ & $12.3 \pm 1.3$ & $13.4 \pm 1.1$ & 8.9 & $\mathrm{P}>0.05$ & $11.8 \pm 1.5$ & $15.9 \pm 1.3$ & 34.8 & $\mathrm{P}<0.05$ \\
\hline
\end{tabular}

Statistical analysis:

During the pedagogical research, Microsoft excel 2016 and biostat 2009 programs were used. Statistical processing of the results was performed using the biostat 2009 program, wherein the parametric t-student criterion, the reliability of the results was considered at $\mathrm{P}<0.05$. Mathematical processing and the average value of indicators in groups was determined using Microsoft excel 2016 [24-25].

\section{Results}

Prior to the pedagogical study, all schoolchildren took the "Shuttle run $3 \times 10 \mathrm{~m}$ " and "Turns on the gym bench" control tests. The results of the average indicators were not significantly significant. After the end of the experiment, the difference between the indicators in both tests changed in both groups (table 2).

Table 2 shows that at the end of the pedagogical study, the indicators of both CG and EG improved. However, the increase in results was different. Class $3 \mathrm{~A}$ schoolchildren did not significantly improve their performance in the "Shuttle run" test from 10.2 \pm 0.6 to $9.9 \pm 0.5(\mathrm{P}>0.05)$. And in the test for vestibular stability, the indicators of children from CG improved by only $2.9 \%(\mathrm{P}>0.05)$. The results of children's training in CG may indicate the effectiveness of using a standard physical education program for primary school children.

However, the results of training of children from EG indicate a more effective work in physical education lessons with the introduction of exercise Classics for each lesson. Thus, the indicators of children from class $3 \mathrm{~A}$ in the test for coordination abilities improved from $9.9 \pm 0.5$ to $8.5 \pm 0.4 \quad(\mathrm{P}<0.05)$, and the indicators of vestibular stability in the test "Turns on the gym bench" improved by $34.8 \%(\mathrm{P}<0.05)$. Thus, the exercise Classics not only allows you to develop coordination abilities more effectively, but also the vestibular stability of children of primary school age.

\section{Discussion}

Modern and unfavorable environmental conditions have a large negative impact on the growth and development of the human body. A lot of research has been devoted to healthy lifestyles, but the importance of physical exercise for a person should be highlighted separately. Physical culture is a set of exercises aimed at comprehensive harmonious development of people and their adaptive preparation for life. Important knowledge of physical education is shown at school age. A physical education lesson at school is a mandatory subject, and the results of schoolchildren activities in the lessons are summed up annually [5-6, 26].

The standard physical education program at school covers a significant set of movements and exercises that a schoolchild learns during school [7]. Some authors believe that the standard program does not need to be supplemented, but completely replaced with another method or several sets of exercises [11-12, 27]. This extraordinary measure, in our opinion, is not quite correct. The curriculum for secondary schools needs only minor additions. For example, the exercise Classics, which was studied earlier, proved to be positive. The effectiveness of introducing exercise Classics in the educational process of physical education for children of primary school age is proved. This exercise increases the motor density of physical education classes, improves the emotional background of schoolchildren and develops them physically [8]. This study confirms the relationship between physical abilities and cognitive and mental processes that were previously identified [17-19, 28].

In a new study, the effectiveness of the influence of exercise Classics not only on the development of coordination processes, but also on the vestibular stability of schoolchildren has been proved.

Separately, we should note the effectiveness of using a differentiated approach in working with children. This approach is of great importance to schoolchildren's individual development. The effectiveness of this approach has been confirmed by previous studies [9-10; 29].

The effectiveness of introducing exercise Classics in the educational process of schoolchildren during the sensitive period of development of coordination abilities, which is noted by many authors, is also worth noting. It is the primary school age that is most favorable for the development of most children's abilities [13, 30].

The topic is relevant because some recent studies emphasize the importance of the topic of motor activity of young people [31] and health education [32]. 


\section{Conclusions}

If schoolchildren perform exercise Classics at each physical education lesson at school, then they will improve not only coordination abilities, but also vestibular stability. Such research is effective, relevant and promising for further study of physical and mental abilities of schoolchildren of different ages.

\section{REFERENCES}

[1] Lelonek M, Przychodni A. Level of physical activity during school recess within aspect of available dedicated playing space. Phys Activ Rev 2020; 8(2): 30-37. doi: 10.16926/par.2020.08.19

[2] Nemček D, Pačesova P, Smela P, Ladecka L, Harcarikova T. Health status differences in subjective well-being of male and female high school students preferring sedentary leisure activities. Phys Activ Rev 2020; 8(2): 1-8. doi: 10.16926/par.2020.08.15

[3] Atkinson M. Physical cultural studies [Redux]. Sociology of Sport Journal 2011; 28(1): 135-144. https://doi.org/10.1123 /ssj.28.1.135

[4] Gregor S, Janko S. Influence of the quality implementation of a physical education curriculum on the physical development and physical fitness of children. BMC public health 2012; 12. https://doi.org/10.1186/1471-2458-12-61

[5] Chen S, Kim Y, Gao Z. The contributing role of physical education in youth's daily physical activity and sedentary behavior. BMC Public Health 2014; 14. https://doi.org/10.1 186/1471-2458-14-110

[6] Wallhead T, Garn A, Vidoni C. Sport Education and social goals in physical education: relationships with enjoyment, relatedness, and leisure-time physical activity. Physical Education and Sport Pedagogy 2012; 18(4): 427-441. https://doi.org/10.1080/17408989.2012.690377

[7] Lyakh VI. Physical culture. Grades 1-4: Textbook for general education institutions. - Moscow: Education 2013; $190 \mathrm{p}$.

[8] Polevoy G.G. Development of Coordination Abilities with Use of Classic's Exercises. International Journal of Medical Research \& Health Sciences 2019; 8(12): 41-45

[9] Breuer C, Hallmann K, Wicker P. (2011). Determinants of sport participation in different sports. Managing Leisure, 16(4): 269-286. https://doi.org/10.1080/13606719.2011.613 625

[10] Barker D, Quennerstedt M, Annerstedt C. Learning through group work in physical education: a symbolic interactionist approach. Sport, Education and Society 2015; 20(5): 604-623. https://doi.org/10.1080/13573322.2014.962493

[11] Dobbins M, Husson H, DeCorby K, LaRocca RL. School-based physical activity programs for promoting physical activity \& fitness in children and adolescents aged 6 to 18. Cochrane Database of Systematic Reviews 2013; 2. https://doi.org/10.1002/14651858.CD007651.pub2
[12] Chiodera P, Volta E, Gobbi G, Milioli MA, Mirandola P, Bonetti A, Delsignore R, Bernasconi S, Anedda A, Vitale M. Specifically designed physical exercise programs improve children's motor abilities. Scandinavian Journal of Medicine and Science in Sports 2008; 18(2): 179-187. https://doi.org/10.1111/j.1600-0838.2007.00682.x

[13] Viru A, Loko J, Harro M, Volver A, Laaneots L, Viru M. Critical Periods in the Development of Performance Capacity During Childhood and Adolescence. European Journal of Physical Education 2006; 4(1): 75-119. https://doi.org/10.1080/1740898990040106

[14] Tuchak O. Influence of Coordination Exercises on Elementary Schoolchildren with Mental Retardation. Novelty. Physical Education, Sports and Health Culture in Modern Society 2018; 42(2): 78-85. DOI: https://doi.org/10 .29038/2220-7481-2018-02-78-85

[15] Lyakh VI, Sadowski J, Witkowski Z. Development of coordination motor abilities (CMA) in the system of long-term preparation of athletes. Polish Journal of Sport and Tourism 2011; 18(3): 187-191. https://doi.org/10.2478/ v10197-011-0014-6

[16] Shawkat R. The impact of development of the special coordination abilities on the general skill ability for table tennis juniors under 12 years old. International journal of science culture and sport 2014; 2(2): 30-42. https://doi.org/10.14486/ijscs71

[17] Pietsch, S, Böttcher, C, Jansen P. Cognitive Motor Coordination Training Improves Mental Rotation Performance in Primary School-Aged Children. Mind, Brain, and Education 2017; 11(4): 176-180 https://doi.org/10.1111 /mbe. 12154

[18] Ruiz-Ariza A, Grao-Cruces A, Marques De Loureiro NE, Martinez-Lopez EJ. Influence of physical fitness on cognitive and academic performance in adolescents: A systematic review from 2005-2015. International Review of Sport and Exercise Psychology 2016; 10(1): 108-133. https://doi.org/10.1080/1750984X.2016.1184699

[19] Chaddock-Heyman L, Hillman CH, Cohen NJ, Kramer AF. The importance of physical activity and aerobic fitness for cognitive control and memory in children. Monographs of the Society for Research in Child Development 2014; 79(4): 25-50. https://doi.org/10.1111/mono.12129

[20] Trudeau F, Shephard RJ. School physical activity, school sports and academic performance. International Journal of Behavioral Nutrition and Physical Activity 2008; 5. https://doi.org/10.1186/1479-5868-5-10

[21] Carral, JMC, Ayán C, Espiño MJS. The relationship between physical fitness and academic performance in spanish secondary education students: A longitudinal study. Cultura, Ciencia y Deporte 2016; 11: 7-16. Doi 10.12800/ccd.v11i3 1.638

[22] Polevoy GG. Training of motor rhythm in students, practicing football. Physical education of students 2017; 21(4): 189-192. https://doi.org/10.15561/20755279.2017.04 07

[23] Georgy G Polevoy. The Development of the Vestibular Stability in Children Who are Engaged in Football Taking into Account their Nervous System. Indian Journal of Public Health Research \& Development, February 2019, 10(2): 
$317-322$

[24] Khusainova RM, Shilova ZV, Curteva OV. Selection of appropriate statistical methods for research results processing. Mathematics Education 2016; 11(1): 303-315. DOI: 10.12973/iser.2016.21030a

[25] Tong X, Zhang ZY. Diagnostics of Robust Growth Curve Modeling Using Student's t Distribution. Multivariate behavioral research 2012; 47(4): 493-518. https://doi.org/10 $.1080 / 00273171.2012 .692614$

[26] Carpenter P, Morgan K. Motivational Climate, Personal Goal Perspectives, and Cognitive and Affective Responses in Physical Education Classes. European Journal of Physical Education 1999; 4(1): 31-44. http://dx.doi.org/10.1080/174 0898990040103

[27] Dallolio L, Ceciliani A, Sanna T, Garulli A. Proposal for an Enhanced Physical Education Program in the Primary School: Evaluation of Feasibility and Effectiveness in Improving Physical Skills and Fitness. Journal of physical activity \& health 2016; 13(10): 1024-1034. DOI: 10.1123/jpah.2015-0694

[28] Chang EC-H, Chu C-H, Karageorghis CI, Wang CC, Tsai JH-C, Wang Y-S, Chang Y-K. Relationship between mode of sport training and general cognitive performance. Journal of Sport and Health Science 2017; 6(1): 89-95. https://doi.o $\mathrm{rg} / 10.1016 / \mathrm{j}$.jshs.2015.07.007

[29] Kühnhausen J, Dirk J, Schmiedek F. Individual classification of elementary school children's physical activity: A time-efficient, group-based approach to reference measurements. Behaviour Research Methods 2016; 49(2): 685-697. DOI: 10.3758/s13428-016-0724-2

[30] Charles HZ, Megan RG, Robert BM, Jana MK, Nathan AF. Sensitive Periods. Monographs of the society for research in child development 2011; 76(4): 147-162.http://doi.org/10.1 111/j.1540-5834.2011.00631.x

[31] Linda N. Chukwurah, Oliver I. Abbah , Cylia N. Iweama, John E. Ogugua, Jonathan Ameh, "Students' Achievement in Physical and Health Education: Effect of Discussion Teaching Method," International Journal of Human Movement and Sports Sciences, Vol. 8, No. 3, pp. 86 - 90, 2020. DOI: $10.13189 /$ saj.2020.080302.

[32] Olena Lutsenko, Gregory Lucenko, Maryna Khrolenko, Olesya Mehem , " Defining the Conditions of Forming Students Motivation to Movement Activity," International Journal of Human Movement and Sports Sciences, Vol. 8, No. 4, pp. 117 - 123, 2020. DOI: 10.13189/saj.2020.080403. 